\title{
Effect of the sense of coherence and associated factors in the quality of life of head and neck cancer patients
}

\author{
Laura Izabel Lampert \\ BONZANINI(a) \\ Eloisa Barbieri SOLDERA ${ }^{(b)}$ \\ Gabriela Barbieri ORTIGARA(b) iD $^{(1)}$ \\ Riéli Elis SCHULZ(b) iD \\ Jessica Klöckner KNORST ${ }^{(b)}$ \\ Thiago Machado ARDENGHI(b) iD \\ Kívia Linhares FERRAZZO(c) iD \\ (a) Universidade Federal do Rio Grande do Sul \\ (UFRGS), School of Dentistry, Department \\ of Surgery and Orthopedics, Porto Alegre, \\ RS, Brazil. \\ (b) Universidade Federal de Santa Maria \\ (UFSM), School of Dentistry, Department of \\ Stomatology, Santa Maria, RS, Brazil. \\ (c) Universidade Federal de Santa Maria \\ (UFSM), School of Dentistry, Department of \\ Pathology, Santa Maria, RS, Brazil.
}

Declaration of Interests: The authors certify that they have no commercial or associative interest that represents a conflict of interest in connection with the manuscript.

Corresponding Author:

Laura Izabel Lampert Bonzanini

E-mail: laurabonzanini@hotmail.com

https://doi.org/10.1590/1807-3107bor-2020.vol34.0009

Submitted: June 9, 2019

Accepted for publication: December 10, 2019

Last revision: January 13, 2020
Abstract: The sense of coherence (SOC) is a measure of global orientation regarding the ability of individuals to cope with stressful situations. The aim of the present study was to evaluate the association between SOC and quality of life (QoL) and clinical and sociodemographic characteristics among survivors of oral, oropharynx, hypopharynx, or larynx cancer. A cross-sectional study was conducted with 90 cancer patients in follow up at the Santa Maria University Hospital in southern Brazil who had completed conformal 3D radiotherapy at least three months earlier. QoL was assessed using the University of Washington Quality of Life (UW-QOL) questionnaire and SOC was measured using the Brazilian version of the SOC-13 questionnaire. Data on socio-demographic characteristics and the disease were obtained from patients' charts. Oral clinical conditions were also evaluated. Associations between exploratory variables and mean UW-QOL scores were evaluated through Poisson regression and the results were presented as rate ratios (RR) and 95\% confidence intervals (CI). The mean overall UW-QOL score was $67.90( \pm 18.71)$. Moderate and high SOC scores were associated with higher mean UW-QOL scores, that is, individuals with a stronger SOC demonstrated better QoL, $(p<0.05)$. Regarding the clinical variables, individuals with advanced stage cancer and those with hyposalivation and trismus had poorer QoL $(p<0.05)$. Patients with a greater SOC reported a better quality of life. Our findings show the importance of focusing on psychosocial factors, which can alleviate the impact caused by the disease and improve the QoL of these patients.

Keywords: Head and Neck Neoplasms; Quality of Life; Sense of Coherence.

\section{Introduction}

It is increasingly recognized that numerous factors exert an influence on health and disease. Thus, interest in the psychosocial determinants of general and oral health has increased considerably in recent years. ${ }^{1}$ One such determinant is sense of coherence (SOC), which is a concept that comes from the Salutogenic Theory proposed by Antonovsky. ${ }^{2}$ Contrary to the principles of disease pathogenesis, this theory puts forth the idea of understanding biological methods with an emphasis on prevention. The investigation of SOC constitutes 
an attempt to explain why some individuals remain psychologically healthy even after experiencing stressful life circumstances. ${ }^{2}$

Individuals with a strong SOC evaluate situations in a more comprehensive way, view life events and health/illness problems as challenges worthy of effort, perceive available resources, and are able to use these resources to cope with stress. ${ }^{2}$ Thus, SOC is considered a global guideline that allows individuals to manage stress, identify their internal and external environments, and find solutions for their health problems. ${ }^{2}$ Studies have shown that psychological skills, such as optimism and resilience, are correlated with subjective health measures, such as self-rated health and quality of life (QoL).3,4,5

QoL is defined as a multidimensional, subjective construct that results from the combination of living conditions and individual satisfaction, with emphasis on personal values, aspirations, beliefs, and expectations. ${ }^{6}$ Thus, QoL is an important outcome that results from the interaction between general health conditions and both social and contextual factors. ${ }^{6,7}$ The measurement of QoL is a relatively new approach to the evaluation of individuals with chronic conditions, such as cancer, ${ }^{8}$ of which one of the most traumatic types is head and neck cancer due to the harm caused by the treatment and the psychological trauma that accompanies survival, which is relatively low. ${ }^{9}$

Studies have shown that psychosocial characteristics, such as SOC, can influence the ability of cancer patients to manage the adverse effects of the disease.${ }^{10} \mathrm{~A}$ stronger SOC may be an important ally to promote effective improvements in the general, oral, and subjective health status of these patients.

Although SOC is considered to be an important concept and helps explain the relationship between psychosocial factors and health-related behaviors, the possible relationships between SOC and QoL in survivors of head and neck cancer have not been explored. Thus, the aim of the present study was to evaluate the relationship between QoL and both SOC and clinical/sociodemographic factors among survivors of head and neck cancer. We hypothesized that patients with a stronger SOC are more likely to report better QoL.

\section{Methodology}

This study is reported according to "Strengthening the Reporting of Observational Studies in Epidemiology" (STROBE) guidelines.

\section{Study design and participants}

A cross-sectional study was conducted with 90 survivors of head and neck cancer in follow-up care at the Santa Maria University Hospital after having undergone radiotherapy. The city of Santa Maria is located in southern Brazil and had a population of 278,445 in 2016 (IBGE 2017)..$^{11}$ The Santa Maria University Hospital is the largest public hospital in the interior of the state of Rio Grande do Sul and is a reference center for the treatment of cancer in the central western region of the state, serving a population of 1.2 million inhabitants of 45 municipalities. In the present study, we used a convenience sample, as all patients under care at the head and neck outpatient clinic of the hospital were invited to participate in the study for follow-up visits from April 2016 to May 2017.

The sample size was calculated based on the results of a previous study in which mean UW-QOL scores of individuals with early (I/II) and advanced (III/IV) stage cancer were 1056.84 (SD: 126.85) and 912.50 (SD: 222.38), respectively. ${ }^{12}$ Considering a 95\% confidence interval, $90 \%$ power, 1:1 ratio between unexposed and exposed individuals, and the addition of $20 \%$ to compensate for possible losses, the minimum sample size was 85 individuals.

\section{Inclusion and exclusion criteria}

Male and female patients over 18 years old with a previous diagnosis of squamous cell carcinoma of the oral cavity, oropharynx, hypopharynx, or larynx treated with conformal3D radiotherapy (with or without concomitant chemotherapy) and who had completed radiotherapy at least three months earlier were considered eligible for the study. Patients with disease relapse or a new primary tumor and those with no time to participate in the evaluation and proposed tests were excluded.

\section{Variables}

Quality of life (primary outcome of this study) was measured using the University of Washington Quality 
of Life (UW-QOL) questionnaire, which has been translated and validated for the Portuguese language to evaluate the QoL of patients with head and neck cancer. ${ }^{13}$ The questionnaire consists of 12 multiple choice questions. Each question corresponds to a specific domain (pain, appearance, activity, recreation, swallowing, chewing, speech, shoulders, taste, saliva, mood, and anxiety). Each of the 12 questions has three to five scored response options ranging from 0 to 100 points, with 0 being the worst condition (greatest impact on QoL) and 100 being the highest score, indicating better QoL. In addition to assessing each of the 12 domains individually, the questionnaire also allows an integrated evaluation based on the mean or sum, with higher scores denoting better QoL. ${ }^{12,14}$

To measure and qualify SOC, the patients answered the short version of the 13-item Sense of Coherence (SOC-13) scale, which was originally developed by Antonovsky ${ }^{2}$ and was subsequently translated, adapted, and validated for use in Brazil. $1 .{ }^{15}$ The questions are divided into three components: comprehensibility, manageability, and meaning. Response options are presented on a five-point Likert scale coded 1 to 5 and varying according to the item. The scale was administered by trained interviewers during faceto-face interviews. The answers to items 1, 2, 3, and 13 are reversed so that they have the same meaning as the other answers. The final score is calculated by summing the item scores. The total score ranges from 13 to 65 points, with higher scores denoting a stronger SOC. For the present study, we used the tertiles of SOC distribution to categorize the individuals as having a weak, moderate, or strong SOC. ${ }^{16}$

The clinical variables investigated were tumor staging, hyposalivation, and trismus. Tumor staging was categorized as early (stages I and II) or advanced (stages III and IV). The AJCC staging system $7^{\text {th }}$ edition was used. ${ }^{17}$ Due to sample characteristics, hyposalivation was determined through the evaluation of stimulated salivary flow following the methods proposed by Navazesh and Kumar ${ }^{18}$ and Thomson, ${ }^{19}$ and was recorded when stimulated salivary flow was less than $0.5 \mathrm{~mL} / \mathrm{min} .{ }^{20}$ Trismus was assessed through a clinical examination performed by trained examiners and was recorded when maximum mouth opening was less than or equal to $35 \mathrm{~mm}$ (measured using millimeter ruler) ${ }^{21}{ }^{21}$ For the analysis, trismus was dichotomized as absent (opening $>35 \mathrm{~mm}$ ) or present (opening $\leq 35 \mathrm{~mm}$ ).

The following demographic and socioeconomic variables were collected using a semi-structured questionnaire: sex (male or female), skin color (white or non-white), age, and education level. Age was dichotomized as $\geq 64$ years or $<64$ years (individuals over 64 are considered elderly ${ }^{22}$ ). Education level was dichotomized as $<8$ years (incomplete elementary school) or $\geq 8$ years.

\section{Statistical analyses}

The data were analyzed using the STATA 14 statistical program (StataCorp, 2014; Stata Statistical Software: Release 14.1.; StataCorp LP, College Station, USA). Descriptive statistics were performed for the demographic, socioeconomic, psychosocial, and clinical characteristics of the sample according to the UW-QOL score. Comparisons of the means of the UW-QOL domains and the psychosocial variable (SOC categories) were performed using the KruskalWallis test. Unadjusted analyses were performed to provide a preliminary assessment of the association between predictor variables and the outcome (mean UW-QOL score). The adjusted Poisson regression model was used to evaluate associations between the sample characteristics and mean UW-QOL score. Exploratory variables with a p-value $\leq 0.20$ in the univariate analysis were incorporated into the multivariate model. The results were expressed as rate ratios (RR) and respective 95\% confidence intervals $(\mathrm{CI})$ and the significance level was set at $5 \%(\mathrm{p}<0.05)$.

\section{Ethical considerations}

This study received approval from the Human Research Ethics Committee of the Federal University of Santa Maria (certificate number: 51958915.6.0000.5346). All participants signed a statement of informed consent.

\section{Results}

The sample consisted of 90 survivors of squamous cell carcinoma of the oral cavity, oropharynx, hypopharynx, or larynx. The overall mean UW-QOL score was 67.90 (SD \pm 18.71 ). The 
majority was male $(83.3 \%)$, white $(87.8 \%)$, and aged 64 years or younger $(63.3 \%)$. Most patients received radiotherapy, chemotherapy, and surgery $(40.0 \%)$, followed by radiotherapy and chemotherapy (34.4\%), surgery and radiotherapy $(18.9 \%)$, and $6 \%$ received radiotherapy alone.

The mean UW-QOL scores according to socio-demographic, psychosocial, and clinical characteristics are presented in Table 1. Individuals with a moderate or strong SOC had higher mean UW-QOL scores than individuals with a weak SOC. Regarding the clinical variables, patients with advanced stage tumors and those with hyposalivation and trismus had lower UW-QOL scores, denoting poorer QoL. The mean radiation dose received was 62.99 Gy $( \pm 9.74)$, with $79.49 \%$ of patients receiving a dose $\geq 60 \mathrm{~Gy}$. There was no correlation between the total dose received and the total UW-QOL and SOC scores.

Table 2 displays the overall and domain scores of the UW-QOL questionnaire according to the psychosocial variable (SOC categories). Activity was the only domain significantly associated with SOC $(p=0.047)$. However, the mean domain scores generally increased with the increase in SOC. For instance, individuals with a strong SOC had a higher mean on the anxiety domain $(77.8 \pm 32.8)$ than those with a weak SOC $(61.5 \pm 42.7)$.

Table 3 displays the results of the unadjusted and adjusted Poisson regression analyses associating the exploratory variables with mean UW-QOL scores. In the unadjusted analysis, a moderate $(\mathrm{RR}=1.11 ; 95 \%$ CI: 1.02 to 1.21 ) or strong (RR $=1.24 ; 95 \% \mathrm{CI}: 1.12$ to 1.38) SOC was significantly associated with higher mean UW-QOL scores, meaning that individuals with a stronger SOC had better QoL. Regarding the clinical variables, individuals with advanced stage tumors ( $R R=0.88,95 \%$ CI: 0.81 to 0.95$)$, hyposalivation $(\mathrm{RR}=0.84 ; 95 \% \mathrm{CI}: 0.77$ to 0.90$)$, and trismus ( $\mathrm{RR}=0.87$; $95 \%$ CI: 0.81 to 0.94 ) had $12 \%, 16 \%$, and $13 \%$ lower mean UW-QOL scores, respectively, denoting poorer QoL.

\section{Discussion}

The present results support the hypothesis that psychosocial factors influence the QoL of
Table 1. Sample distribution of sum UW-QOL scores according to sociodemographic, psychosocial and clinical characteristics of the sample $(n=90)$.

\begin{tabular}{|c|c|c|}
\hline Variables & n (\%) & SUM (SD) \\
\hline \multicolumn{3}{|c|}{ Demographic and socioeconomic variables } \\
\hline \multicolumn{3}{|c|}{ Sex } \\
\hline Male & $75(83.3)$ & $818.4(223.3)$ \\
\hline Female & $15(16.7)$ & $797.2(238.3)$ \\
\hline \multicolumn{3}{|l|}{ Skin color } \\
\hline White & $79(87.8)$ & $817.3(229.5)$ \\
\hline Non-white & $11(12.2)$ & 796.9 (193.5) \\
\hline \multicolumn{3}{|l|}{ Age } \\
\hline$<64$ years & $57(63.3)$ & $767.4(231.2)$ \\
\hline$>64$ years & $33(36.7)$ & $896.7(189.2)$ \\
\hline \multicolumn{3}{|l|}{ Education } \\
\hline$<8$ years & $87(92.2)$ & $817.8(230.4)$ \\
\hline$>8$ years & $3(7.8)$ & $779.7(145.2)$ \\
\hline \multicolumn{3}{|c|}{ Psychosocial variable } \\
\hline \multicolumn{3}{|c|}{ Sens of coherence } \\
\hline Low & $13(25.5)$ & $720.3(192.4)$ \\
\hline Middle & $26(51.0)$ & $808.4(201.9)$ \\
\hline High & $12(23.5)$ & $914.2(234.1)$ \\
\hline \multicolumn{3}{|c|}{ Clinical variables } \\
\hline \multicolumn{3}{|l|}{ Cancer staging } \\
\hline Initial & $27(30.3)$ & $909(202.2)$ \\
\hline Advanced & $62(69.7)$ & $771(223.9)$ \\
\hline \multicolumn{3}{|l|}{ Hyposalivation } \\
\hline Not & $20(22.7)$ & 957.2 (178.8) \\
\hline Yes & 68 (77.3) & $775.6(218.0)$ \\
\hline \multicolumn{3}{|l|}{ Trismus } \\
\hline Absent & $42(48.8)$ & $895.3(165.9)$ \\
\hline Present & $44(51.2)$ & $733.2(238.7)$ \\
\hline
\end{tabular}

Values lower than 90 due to missing data; ${ }^{\circ} \mathrm{SD}$, standard deviation.

cancer patients, as individuals with a stronger SOC reported better overall QoL. The findings also suggest that clinical features, such as trismus, hyposalivation, and advanced-stage cancer, are related to poorer QoL.

A moderate to strong SOC was associated with better QoL. This association may be explained by the subjective characteristic of the SOC-13 scale. Many studies show that $\mathrm{SOC}$ is positively associated with a low level of stress and a better capacity to cope with stressful situations. ${ }^{4}$ The literature has also shown that psychological skills, such as optimism and resilience, are correlated with subjective health 
Table 2. Sample distribution of overall and domains UW-QOL scores according to psychosocial variable (SOC categories).

\begin{tabular}{lcccc}
\hline UW-QOL & Low SOC & Middle SOC & High SOC & p-value* \\
\hline Domains [mean (SD) $\left.{ }^{a}\right]$ & & & & \\
$\quad$ Pain & $61.5( \pm 29.9)$ & $74.0( \pm 30.3)$ & $78.0( \pm 30.5)$ & 0.347 \\
Appearance & $67.3( \pm 29.5)$ & $77.8( \pm 16.3)$ & $75.0( \pm 26.1)$ & 0.667 \\
Activity & $59.6( \pm 19.1)$ & $68.0( \pm 26.9)$ & $83.3( \pm 19.4)$ & 0.047 \\
Recreation & $59.6( \pm 33.1)$ & $70.1( \pm 28.3)$ & $83.3( \pm 26.8)$ & 0.165 \\
Swallowing & $59.0( \pm 24.3)$ & $68.3( \pm 29.1)$ & $66.8( \pm 28.4)$ & 0.505 \\
Chew & $46.1( \pm 32.0)$ & $63.4( \pm 33.3)$ & $75.0( \pm 33.0)$ & 0.133 \\
Speech & $64.0( \pm 34.6)$ & $65.4( \pm 33.3)$ & $75.0( \pm 25.1)$ & 0.739 \\
Shoulder & $71.7( \pm 30.0)$ & $60.1( \pm 38.9)$ & $86.0( \pm 26.5)$ & 0.162 \\
Taste & $51.1( \pm 57.6)$ & $62.7( \pm 39.3)$ & $72.1( \pm 37.2)$ & 0.436 \\
Saliva & $51.2( \pm 29.3)$ & $51.1( \pm 27.2)$ & $58.2( \pm 40.5)$ & 0.872 \\
Humor & $67.3( \pm 34.4)$ & $78.8( \pm 27.1)$ & $83.3( \pm 30.7)$ & 0.368 \\
Anxiety & $61.5( \pm 42.7)$ & $68.0( \pm 37.1)$ & $77.8( \pm 32.8)$ & 0.660 \\
Overall [mean (SD) $\left.{ }^{\circ}\right]$ & $60.0( \pm 16.0)$ & $67.3( \pm 16.8)$ & $76.1( \pm 19.5)$ & 0.056 \\
\hline
\end{tabular}

"Kruskal-Wallis test; ${ }^{a} \mathrm{SD}$, standard deviation

measures and individuals with a strong SOC have a good perception of their health as well as better general and oral health-related QoL. ${ }^{23}$ The findings suggest that patients with a stronger SOC have better QoL and are consequently better able to cope with the consequences and adverse effects of cancer treatment and disease survival. However, the lack of previous studies associating SOC with QoL in survivors of head and neck cancer impedes the comparison of the results.

One question that remains undefined is whether patients who had head and neck cancer undergo experiences that influence SOC that non-cancer patients would not have. Schnyder et al. ${ }^{24}$ found a possible answer through the analysis of SOC in accident victims and patients with chronic diseases, concluding that the victims' scores decreased significantly after the occurrence; in contrast, SOC in patients with chronic diseases remained constant. ${ }^{24}$ The authors state that sudden events can alter a person's view of the world, consequently altering SOC. A study with spouses of women with breast cancer specifically evaluated this outcome (how the news influenced SOC in the primary caregiver), finding a strong association between a weak SOC and the traumatic event..$^{25}$ This leads us to conclude that it is important to assess the impact of the diagnosis of head and neck cancer on patients as well as its effect on their SOC, given the influence of traumatic life experiences on the variability of SOC.

Patients with advanced-stage tumors had lower mean UW-QOL scores, denoting poorer QoL. Rana et al. ${ }^{26}$ found similar results. This negative impact on QoL may be explained by the more aggressive procedures that are used in the treatment of patients in advanced stages of the disease. ${ }^{26}$ Such patients are submitted to more invasive surgeries and higher doses of radiotherapy, which may contribute to an increase in tissue damage, ${ }^{27}$ impacting directly on wellbeing and QoL. In this study, no association was found between the total radiation dose received and the quality of life or SOC. This may be justified by the fact that most of the sample received high doses of radiation.

Clinical features, such as hyposalivation and trismus, were also associated with QoL. Hyposalivation is associated with the cytotoxic effect of radiotherapy, which causes cell death and fibrosis in the salivary glands and a consequent reduction in salivary flow. ${ }^{28}$ Thus, this association may be explained by the discomfort triggered by reduced salivary flow, which makes chewing and swallowing difficult and alters the sense of taste, leading to poorer QoL. Patients with trismus also reported poorer QoL, which is in agreement with findings described in previous studies. ${ }^{29,30,31}$ Besides hindering eating, difficulty 
Effect of the sense of coherence and associated factors in the quality of life of head and neck cancer patients

Table 3. Unadjusted and adjusted association between independents variables and overall UW-QOL scores, determined using poisson regression.

\begin{tabular}{|c|c|c|c|}
\hline \multirow{2}{*}{ Variables } & Unadjusted & \multirow{2}{*}{ p-value } & Adjusted \\
\hline & $\mathrm{RR}^{\mathrm{a}}\left(\mathrm{Cl}^{\mathrm{b}} 95 \%\right)$ & & $\mathrm{RR}^{\mathrm{a}}\left(\mathrm{Cl}^{\mathrm{b}} 95 \%\right)$ \\
\hline \multicolumn{4}{|c|}{ Demographic and socioeconomic variables } \\
\hline \multicolumn{4}{|l|}{ Sex } \\
\hline Male & 1 & \multirow[t]{2}{*}{0.448} & - \\
\hline Female & $0.97(0.91-1.04)$ & & \\
\hline \multicolumn{4}{|l|}{ Skin color } \\
\hline White & 1 & \multirow[t]{2}{*}{0.520} & - \\
\hline Non-white & $0.97(0.90-1.05)$ & & \\
\hline \multicolumn{4}{|l|}{ Age } \\
\hline$<64$ years & 1 & \multirow[t]{2}{*}{0.000} & 1 \\
\hline$>64$ years & $1.16(1.11-1.22)$ & & $0.99(0.92-1.07)$ \\
\hline \multicolumn{4}{|l|}{ Education } \\
\hline$<8$ years & 1 & \multirow[t]{2}{*}{0.327} & - \\
\hline$>8$ years & $0.95(0.86-1.04)$ & & \\
\hline \multicolumn{4}{|c|}{ Psychosocial variable } \\
\hline \multicolumn{4}{|c|}{ Sens of coherence } \\
\hline Low & 1 & \multirow{3}{*}{0.000} & 1 \\
\hline Middle & $1.12(1.03-1.22)$ & & $1.11(1.02-1.21)^{*}$ \\
\hline High & $1.26(1.15-1.39)$ & & $1.24(1.12-1.38)^{* *}$ \\
\hline \multicolumn{4}{|c|}{ Clinical variables } \\
\hline \multicolumn{4}{|l|}{ Cancer staging } \\
\hline Initial & 1 & 0.000 & 1 \\
\hline Advanced & $0.84(0.80-0.89)$ & & $0.88(0.81-0.95)^{* *}$ \\
\hline \multicolumn{4}{|l|}{ Hyposalivation } \\
\hline Not & 1 & 0.000 & 1 \\
\hline Yes & $0.81(0.76-0.85)$ & & $0.84(0.77-0.90)^{* *}$ \\
\hline \multicolumn{4}{|l|}{ Trismus } \\
\hline Absent & 1 & 0.000 & 1 \\
\hline Present & $0.81(0.77-0.86)$ & & $0.87(0.81-0.94)^{* *}$ \\
\hline
\end{tabular}

chewing caused by limited mouth opening directly interferes with the patient's social interactions, causing weight loss, isolation, and depression, ${ }^{29}$ with a consequent reduction in QoL.

The present study has limitations that should be considered. The cross-sectional design does not enable the determination of the cause-and-effect relationship between the independent variables and QoL, since patients were assessed at a single time. However, this type of study allows the identification of possible risk indicators to be explored in future studies. Another limitation is the absence of a control group. However, comparing the findings to previous studies, the mean QoL scores were slightly lower than those found in groups without disease, ${ }^{32}$ which strengthens the validity of our findings. On the other hand, the study also has strengths, since it involved survivors of head and neck cancer and considered both psychosocial and clinical factors. Although significant results were found related to clinical variables, when assessing all effect measures together, the aspect that exerted the most impact on QoL was the psychosocial factor, in accordance with previous studies that evaluated the SOC and compared with other cancers. Recently, it was demonstrated that the change in the different dimensions of quality of life of cancer patients were mediated by SOC, , $^{33}$ 
showing that it helps in coping with the problem, as a "resistance resource", which positively reflects in the quality of life. Thus, SOC can be considered an important tool to identify cancer patients with greater difficulty in adapting to treatment.

Therefore, the study of SOC is especially important in the oncology population, as it may considerably reduce the impact of the disease on QoL and help patients experience life and treatment in a more manageable, comprehensible, and meaningful way.

\section{Conclusion}

SOC was associated with QoL, as patients with a moderate or strong SOC had better QoL than patients with a weak SOC. Patients who had advanced tumor staging, hyposalivation, and trismus had worse QoL. Given the psychosocial nature of SOC, our findings show the importance of focusing on multidisciplinary actions that stabilize or improve SOC, which could alleviate the impact caused by the disease and improve the QoL of these patients.

\section{References}

1. Scheerman JF, Loveren C, Meijel B, Dusseldorp E, Wartewig E, Verrips GH, et al. Psychosocial correlates of oral hygiene behaviour in people aged 9 to 19 - a systematic review with meta-analysis. Community Dent Oral Epidemiol. 2016 Aug;44(4):331 -41. https://doi.org/10.1111/cdoe.12224

2. Antonovsky A. Unraveling. Mystery of health: how people manage stress and stay well. San Francisco: Jossey-Bass; 1987.

3. Karlsson I, Berglin E, Larsson PA. Sense of coherence: quality of life before and after coronary artery bypass surgery-a longitudinal study. J Adv Nurs. 2000 Jun;31 (6):1383-92. https://doi.org/10.1046/j.1365-2648.2000.01408.x

4. Eriksson M, Lindström B. Antonovsky's sense of coherence scale and the relation with health: a systematic review. J Epidemiol Community Health. 2006 May;60(5):376-81. https://doi.org/10.1136/jech.2005.041616

5. Baker SR, Mat A, Robinson PG. What psychosocial factors influence adolescents' oral health? J Dent Res. 2010 Nov;89(11):1230-5. https://doi.org/10.1177/0022034510376650

6. Post MW. Definitions of quality of life: what has happened and how to move on. Top Spinal Cord Inj Rehabil. 2014;20(3):167-80. https://doi.org/10.1310/sci2003-167

7. Felce D, Perry J. Quality of life: its definition and measurement. Res Dev Disabil. 1995 Jan-Feb;16(1):51-74. https://doi.org/10.1016/0891-4222(94)00028-8

8. Cramp F, James A, Lambert J. The effects of resistance training on quality of life in cancer: a systematic literature review and meta-analysis. Support Care Cancer. 2010 Nov;18(11):1367-76. https://doi.org/10.1007/s00520-010-0904-z

9. Rogers SN, Hannah L, Lowe D, Magennis P. Quality of life 5-10 years after primary surgery for oral and oro-pharyngeal cancer. J Craniomaxillofac Surg. 1999 Jun;27(3):187-91. https://doi.org/10.1016/S1010-5182(99)80049-3

10. Mehanna HM, De Boer MF, Morton RP. The association of psycho-social factors and survival in head and neck cancer. Clin Otolaryngol. 2008 Apr;33(2):83-9. https://doi.org/10.1111/j.1749-4486.2008.01666.x

11. Instituto Brasileiro de Geografia e Estatística - IBGE. Síntese de indicadores sociais: uma análise das condições de vida da populaçãoo brasileira. Rio de Janeiro: Instituto Brasileiro de Geografia e Estatística; 2017.

12. Oliveira RL, Santos RF, Carvalho SH, Agripino GG, Canto MM, Carvalho MV, et al. Prospective evaluation of quality of life in patients with head and neck cancer. Oral Surg Oral Med Oral Pathol Oral Radiol. 2017 Mar;123(3):350-7. https://doi.org/10.1016/i.00oo.2016.11.021

13. Vartanian JG, Carvalho AL, Yueh B, Furia CL, Toyota J, McDowell JA, et al. Brazilian-Portuguese validation of the University of Washington Quality of Life Questionnaire for patients with head and neck cancer. Head Neck. 2006 Dec;28(12):1115-21. https://doi.org/10.1002/hed.20464

14. Andrade FP, Biazevic MG, Toporcov TN, Togni J, Carvalho MB, Antunes JL. Discriminant validity of the University of Washington quality of life questionnaire in the Brazilian context. Rev Bras Epidemiol. 2012 Dec;15(4):781-9. https://doi.org/10.1590/S1415-790X2012000400010

15. Bonanato K, Scarpelli AC, Goursand D, Mota JP, Paiva SM, Pordeus IA. Sense of coherence and dental caries experience in preschool children from Belo Horizonte city. J Dent Sci. 2008;23(3):251-5.

16. Bernabé E, Watt RG, Sheiham A, Suominen-Taipale AL, Uutela A, Vehkalahti MM, et al. Sense of coherence and oral health in dentate adults: findings from the Finnish Health 2000 survey. J Clin Periodontol. 2010 Nov;37(11):981-7. https://doi.org/10.1111/j.1600-051X.2010.01604.x

17. Edge SB, Compton CC. The American Joint Committee on Cancer: the 7th edition of the AJCC cancer staging manual and the future of TNM. Ann Surg Oncol. 2010 Jun;17(6):1471-4. https://doi.org/10.1245/s10434-010-0985-4

18. Navazesh M, Kumar SK; University of Southern California School of Dentistry. Measuring salivary flow: challenges and opportunities. J Am Dent Assoc. 2008 May;139 Suppl:35S-40S. https://doi.org/10.14219/jada.archive.2008.0353 
Effect of the sense of coherence and associated factors in the quality of life of head and neck cancer patients

19. Thomson WM. Dry mouth and older people. Aust Dent J. 2015 Mar;60(1 Suppl 1):54-63. https://doi.org/10.1111/adj.12284

20. Sreebny LM. Saliva in health and disease: an appraisal and update. Int Dent J. 2000 Jun;50(3):140-61. https://doi.org/10.1111/j.1875-595X.2000.tb00554.x

21. Dijkstra PU, Huisman PM, Roodenburg JL. Criteria for trismus in head and neck oncology. Int J Oral Maxillofac Surg. 2006 Apr;35(4):337-42. https://doi.org/10.1016/j.ijom.2005.08.001

22. World Health Organization - WHO. Oral health surveys: basic methods. Geneve: World Health Organization; 2013.

23. Machado FW, Perroni AP, Nascimento GG, Goettems ML, Boscato N. Does the Sense of Coherence modifies the relationship of oral clinical conditions and Oral Health-Related Quality of Life? Qual Life Res. 2017 Aug;26(8):2181-7. https://doi.org/10.1007/s11136-017-1558-9

24. Schnyder U, Büchi S, Sensky T, Klaghofer R. Antonovsky's sense of coherence: trait or state? Psychother Psychosom. 2000 NovDec;69(6):296-302. https://doi.org/10.1159/000012411

25. Shor V, Grinstein-Cohen O, Reinshtein J, Liberman O, Delbar V. Health-related quality of life and sense of coherence among partners of women with breast cancer in Israel. Eur J Oncol Nurs. 2015 Feb;19(1):18-22. https://doi.org/10.1016/i.ejon.2014.08.004

26. Rana M, Kanatas A, Herzberg PY, Khoschdell M, Kokemueller H, Gellrich NC, et al. Prospective study of the influence of psychological and medical factors on quality of life and severity of symptoms among patients with oral squamous cell carcinoma. Br J Oral Maxillofac Surg. 2015 Apr;53(4):364-70. https://doi.org/10.1016/i.bjoms.2015.01.019

27. Vissink A, Jansma J, Spijkervet FK, Burlage FR, Coppes RP. Oral sequelae of head and neck radiotherapy. Crit Rev Oral Biol Med. 2003;14(3):199-212. https://doi.org/10.1177/154411130301400305

28. Beech N, Robinson S, Porceddu S, Batstone M. Dental management of patients irradiated for head and neck cancer. Aust Dent J. 2014 Mar;59(1):20-8. https://doi.org/10.1111/adj.12134

29. Lee LY, Chen SC, Chen WC, Huang BS, Lin CY. Postradiation trismus and its impact on quality of life in patients with head and neck cancer. Oral Surg Oral Med Oral Pathol Oral Radiol. 2015 Fev;119(2):187-95. https://doi.org/10.1016/i.0000.2014.10.003

30. Scott B, Butterworth C, Lowe D, Rogers SN. Factors associated with restricted mouth opening and its relationship to health-related quality of life in patients attending a Maxillofacial Oncology clinic. Oral Oncol. 2008 May;44(5):430-8. https://doi.org/10.1016/j.oraloncology.2007.06.015

31. Rapidis AD, Dijkstra PU, Roodenburg JL, Rodrigo JP, Rinaldo A, Strojan P, et al. Trismus in patients with head and neck cancer: etiopathogenesis, diagnosis and management. Clin Otolaryngol. 2015 Dec;40(6):516-26. https://doi.org/10.1111/coa.12488

32. Antonovsky A. The structure and properties of the sense of coherence scale. Soc Sci Med. 1993 Mar;36(6):725-33. https://doi.org/10.1016/0277-9536(93)90033-Z

33. Rohani C, Abedi HA, Sundberg K, Langius-Eklöf A. Sense of coherence as a mediator of health-related quality of life dimensions in patients with breast cancer: a longitudinal study with prospective design. Health Qual Life Outcomes. 2015 Dec;13(1):195. https://doi.org/10.1186/s12955-015-0392-4 